\title{
A Informalidade e as Flutuações na Atividade Econômica
}

- GISELE FERREIRA TIRYAKI*

\begin{abstract}
RESUMO
Vários trabalhos empíricos e teóricos apontam para o impacto negativo de um setor informal em expansão sobre o crescimento econômico. Este artigo mostra que a dimensão da economia informal afeta também a volatilidade dos ciclos econômicos. Geralmente, empreendimentos informais não se beneficiam de economias de escala; operam com uma combinação ineficiente de capital e trabalho e têm acesso restrito ao mercado financeiro. Os obstáculos encontrados para alavancagem financeira, por sua vez, dificultam a neutralização nas reduções de fluxo de caixa que ocorrem durante períodos de recessão econômica e fazem com que empreendimentos no setor informal sejam mais propensos ao insucesso. Utilizando a metodologia Generalized Method of Moments, o presente trabalho mostra que países com setores informais mais representativos enfrentam maior volatilidade na produção, investimento e consumo durante os ciclos econômicos.
\end{abstract}

Palavras-Chave

ciclos econômicos, economia informal e instituições legais

\begin{abstract}
Previous theoretical and empirical works have focused on the impact of an enlarging informal sector on growth. This paper shows that the size of the informal economy also affects business cycles volatility. Informal businesses are usually small in size, which prevents them from achieving economies of scale, from operating with the right capital/labor mix, and from having access to credit markets. This lack of access to credit markets hinders informal firms' ability to neutralize the cash flow squeeze arising during recessions, increasing their exposure to fluctuations in economic activity and their likelihood of going bankrupt. Using a Generalized Method of Moments methodology on a cross-country dataset, this paper shows that the larger the informal sector of a country, the greater the volatility experienced in output, investment and consumption over the business cycles.
\end{abstract}

\section{KEYWORDS}

business cycles, informal sector, legal institutions

\section{JEL Classification}

E26, E32

\footnotetext{
+ Gostaria de agradecer os comentários oportunos feitos por Tyler Cowen, Ahmet Tiryaki, Giovani Ferreira e pelos pareceristas anônimos.

* Professora da Universidade Salvador - UNIFACS. E-mail: gisele fsilva@unifacs.br. End. para contato: Rua Ponciano de Oliveira, no. 126 - CEP: 41950-275 - Rio Vermelho - Salvador - Bahia.

(Recebido em outubro de 2006. Aceito para publicação em março de 2007).
} 


\section{INTRODUÇÃA}

A participação do setor informal na atividade econômica vem mostrando uma tendência ascendente em muitos países. De acordo com Maloney (1998, 2003), análises mais tradicionais associam o crescimento do setor informal à presença de rigidez no mercado de trabalho: a incapacidade da economia formal de absorver os elevados custos impostos pela legislação trabalhista leva os trabalhadores dispensados a buscarem posições em empreendimentos do setor informal. Interpretações mais recentes, no entanto, indicam que empreendimentos informais também surgem a partir da decisão de trabalhadores de tornarem-se autônomos, com o intuito de evitar não somente os elevados custos com a legislação trabalhista, mas também a cobrança oficial de impostos e os custos com burocracia e corrupção.

Estudos dos determinantes e impactos da economia formal envolvem obstáculos significativos, principalmente no que se refere à identificação das atividades que fazem parte da economia informal e à mensuração da produção deste setor. A definição mais apropriada da economia informal é aquela elaborada por Lippert e Walker (1997): o setor informal envolve atividades legais e criminosas, desempenhadas por meio de transações monetárias ou por escambo, e que não são declaradas formalmente a entidades governamentais - ver, ainda, Schneider e Enste (2000) e Schneider (2004). O presente trabalho, no entanto, utiliza as estimativas do tamanho do setor informal apresentadas em Schneider (2004). Este autor contabilizou apenas as atividades informais "legais" e que envolveram transações monetárias, como por exemplo, a contratação de trabalhadores sem registro junto a entidades governamentais, evitandose, assim, o pagamento de impostos, e atividades desempenhadas por trabalhadores, mas cujos rendimentos não foram declarados (evasão de impostos). As atividades que não envolveram transações monetárias, como os serviços voluntários, e as atividades criminosas não foram incluídas nas estimativas. ${ }^{1}$

A economia informal é formada, na sua maior parte, por pequenos negócios com acesso restrito ao crédito e impossibilitados de recorrer ao sistema legal para a proteção da propriedade e o cumprimento de contratos, já que não possuem registro junto a entidades governamentais. Uma vasta literatura já demonstrou que países em que o setor informal possui proporções relevantes têm experimentado baixas taxas de crescimento econômico - ver, entre outros, Loayza (1997); Johnson, Kaufmann e Zoido-Lobaton (1999) e Schneider e Enste (2000). Como os negócios informais precisam manter a escala de produção em pequena dimensão, a fim de evitar que sejam identificados pelos órgãos governamentais, não operam com economia de escala ou com uma

l O trabalho de Schneider (2004) foi escolhido como fonte dos dados estatísticos porque é o único que apresenta estimativas do tamanho da economia informal para uma variedade de países desenvolvidos e em desenvolvimento. 
combinação eficiente de capital e trabalho. Conseqüientemente, a obtenção de ganhos de produtividade não é viabilizada. No caso do Brasil, por exemplo, estima-se que a produtividade do setor informal é quase duas vezes menor do que a produtividade do setor formal (ver Mckinsey \& Company, 2004).

Os resultados apresentados neste artigo revelam que países com uma economia informal expressiva tendem a apresentar flutuações mais acentuadas na atividade econômica. A conexão entre o tamanho da economia informal e a volatilidade dos ciclos econômicos pode ser estabelecida teoricamente como uma extensão da literatura que avalia o funcionamento dos mercados financeiros em condições de informação assimétrica (Gertler e Gilchrist, 1994; Hubbard,1997; Bernanke, Gertler e Gilchrist, 1998). Conhecida como a "visão do canal do balanço financeiro" (the balance-sheet channel approach), seus precursores acreditam que choques que afetam a atividade econômica são ampliados pelas imperfeições presentes no mercado financeiro. A capacidade das empresas de neutralizarem o declínio em fluxo de caixa, durante períodos de recessão econômica, com a aquisição de empréstimos varia de acordo com o patrimônio líquido dessas empresas e suas possibilidades de alavancagem financeira.

Por exemplo, considere os impactos de uma política monetária contracionária. O aumento nas taxas de juros: (i) eleva as despesas financeiras com empréstimos já contratados, reduzindo o fluxo de caixa das empresas; (ii) diminui os preços dos ativos, reduzindo o valor dos bens oferecidos como garantia de empréstimos e (iii) desacelera a demanda agregada, reduzindo as receitas das empresas e aumentando a necessidade de financiamento externo ( financing gap). ${ }^{2}$ A redução em caixa e no patrimônio líquido das empresas eleva a diferença entre os custos dos recursos obtidos com terceiros e o custo de oportunidade dos recursos internos (external finance premium), diminuindo a disponibilidade de crédito e ampliando o choque contracionário inicial.

Quanto maior for a dimensão das imperfeições no mercado financeiro, mais significativo será o impacto de choques à atividade econômica sobre as flutuações no volume de empréstimos, nos gastos e nos investimentos. Gertler e Gilchrist (1994) e Bernanke, Gertler e Gilchrist (1998), por exemplo, demonstraram que o impacto de um choque à política monetária difere entre firmas de portes diversos. Esses autores provêm evidência empírica de que empresas de pequeno porte enfrentam maiores restrições no acesso ao crédito, em face do tamanho reduzido de seu patrimônio líquido e dos maiores custos de informação associados a empréstimos sem respaldo de garantia concedidos por instituições financeiras. ${ }^{3}$ Em resposta à diminuição no fluxo

2 A diferença entre a necessidade e a disponibilidade interna de recursos aumenta porque, no curto prazo, os custos tendem a se ajustar lentamente.

3 Este é um exemplo clássico de risco moral (moral hazard). Como empresas de pequeno porte possuem um patrimônio líquido reduzido, a maior parte dos recursos necessários para implementação de projetos advém de instituições financeiras. Quanto menor for a fração do projeto financiado com recursos 
de caixa, empresas pequenas reduzem seus estoques, produção, nível de emprego e preços. Grandes empresas, por sua vez, respondem à redução no fluxo de caixa através de aumentos em financiamentos de curto prazo e estoques, mantendo o nível de emprego e produção, pelo menos temporariamente (empresas de grande porte têm acesso ao mercado de commercial paper e a outras fontes de financiamento que são inacessíveis a pequenos empreendedores).

Por conseqüência, mercados caracterizados pela predominância de firmas de pequeno porte enfrentam flutuações econômicas mais acentuadas. Empresas que operam no setor informal, por sua vez, possuem uma posição financeira mais precária ainda, visto que têm acesso restrito ao mercado de crédito formal. Quando empreendimentos informais têm acesso a recursos de terceiros, isto normalmente ocorre através de financiadores ilegais, que disponibilizam pequeno volume de recursos a taxas de juros relativamente elevadas (ver Loayza, 1997; Dabla-Norris e Feltstein, 2003; Maloney, 2003; e Farrell, 2004). ${ }^{4}$ Portanto, empresas que operam no mercado informal tendem a operar em escala subótima, são improdutivas e possuem maior probabilidade de insucesso, pois não têm meios para suavizar as flutuações em fluxos de caixa.

Espera-se, portanto, que países com uma economia informal expressiva enfrentem ciclos econômicos mais voláteis, principalmente quando se leva em consideração a interconexão que existe entre os setores formal e informal. Bajada (2003), por exemplo, utilizando dados estatísticos da Austrália, demonstrou que choques negativos no setor formal têm impacto maior sobre o setor informal do que choques positivos; ou seja, a economia informal aumenta a severidade das recessões e, conseqüentemente, a volatilidade dos ciclos econômicos. Schneider e Enste (2000), por sua vez, indicam que mais de $66 \%$ da renda da economia informal é direcionada a gastos no setor formal, fazendo com que qualquer redução ou expansão da atividade econômica que afete o setor informal diminua a demanda pela produção formal.

Em virtude da possibilidade de que o tamanho do setor informal e a volatilidade dos ciclos econômicos possam estar sendo determinados por um terceiro fator, como, por exemplo, o crescimento econômico, sugere-se o uso de variáveis instrumentais. 5 Utilizando dados estatísticos de vários países em formato cross-section, o presente estudo emprega a metodologia Generalized Method of Moments para demonstrar que

internos, maior será a probabilidade de uma determinada empresa incorrer em maiores riscos, afinal menos recursos próprios estão sendo investidos. Este comportamento, por sua vez, aumenta a propensão do projeto ao insucesso.

4 Em países industrializados, atividades formais e informais normalmente ocorrem no âmbito de uma única empresa (ver Gërxhani, 2004). Por conseqüência, as limitações no acesso ao crédito não são tão severas quanto em países em desenvolvimento, mas as condições de crédito são mais restritas do que as enfrentadas por empresas que operam formalmente.

5 Existe evidência empírica de que países com elevadas taxas de crescimento exibem ciclos econômicos menos voláteis (ver Barro, 1991; e Ramey e Ramey, 1994) e possuem uma economia informal menos representativa (Loayza, 1997; Johnson, Kaufmann e Zoido-Lobaton, 1999; Schneider e Enste, 2000). 
quanto maior for o setor informal de um país, mais pronunciadas serão as flutuações nas atividades econômicas.

Estabelecer um vínculo entre o tamanho do setor informal e a volatilidade dos ciclos econômicos é relevante em termos de política econômica, visto que países com flutuações expressivas na atividade econômica tendem a apresentar baixas taxas de crescimento econômico e de investimento, menor volume de investimentos diretos estrangeiros e menores taxas de emprego (ver Aisenman, 1997 e 2003).

O artigo está estruturado da seguinte forma: a primeira seção descreve as variáveis utilizadas nos testes empíricos, enquanto a segunda detalha questões da metodologia econométrica utilizada; a terceira seção analisa os resultados encontrados; a seção seguinte considera a robustez destes resultados e a última seção apresenta as conclusões.

\section{DADOS ESTATÍSTICOS}

Os testes econométricos foram realizados em duas amostras com dados estatísticos de diversos países, em formato cross-section. ${ }^{6}$ A escolha dos países incluídos foi determinada pela disponibilidade de informações. A primeira amostra contém dados de 42 países para o período entre 1961 e 2002, enquanto a segunda amostra contém informações de 45 países para o período entre 1985 e 2002..$^{7}$ Os motivos desta estratégia serão discutidos abaixo, na seção dedicada à metodologia.

A maior parte dos dados estatísticos foi obtida de várias edições da publicação International Financial Statistics Yearbook - IFS (Fundo Monetário Internacional). Em caso de inconsistência nos dados entre as diversas edições, as séries históricas foram combinadas, mantendo-se os valores obtidos na edição mais recente consultada (2003). Fontes alternativas de dados estatísticos serão indicadas no decorrer do trabalho.

\subsection{O Tamanho da Economia Informal}

As estimativas do tamanho do setor informal utilizadas aqui foram obtidas em Schneider (2004). O autor apresenta três observações para o tamanho do setor infor-

6 A ausência de dados estatísticos anuais para o tamanho da economia informal inviabiliza a condução de análise de dados em painel.

7 No Apêndice 1, encontra-se a relação dos países inclusos em cada amostra, bem como os dados numéricos e as estatísticas básicas das variáveis representando o tamanho do setor informal e a volatilidade da produção, investimento e consumo de cada amostra. 
mal de diversos países desenvolvidos e em desenvolvimento, em termos de percentual do Produto Interno Bruto (PIB): 1999/2000, 2001/2002 e 2002/2003. Como os dados estatísticos das demais variáveis foram obtidos até 2002 , utilizou-se a média aritmética das duas primeiras observações como estimativa da dimensão da economia informal de cada país (INFORMAL).

Estimar a dimensão da economia informal é uma tarefa difícil e todos os métodos desenvolvidos até agora possibilitam apenas a obtenção de indicadores aproximados. De uma forma geral, existem três diferentes metodologias utilizadas nas estimativas da magnitude do setor informal: métodos diretos, métodos indiretos e métodos que envolvem o delineamento de modelos estruturais. Os métodos diretos envolvem o uso de amostras de dados obtidas através de respostas voluntárias a enquetes ou auditoria da cobrança de impostos. Os métodos indiretos, por sua vez, utilizam indicadores macroeconômicos que contêm informação da evolução da economia informal para derivar as estimativas (dentre os métodos indiretos, destacam-se o método do insumo físico e o método da demanda por moeda). Enquanto os métodos diretos e indiretos utilizam apenas um indicador para estimar todo o escopo da economia informal, os métodos que utilizam modelos estruturais assumem que o impacto da economia informal ocorre simultaneamente em vários aspectos da economia.

Para uma discussão extensiva dessas metodologias, inclusive de suas vantagens e desvantagens, ver, dentre outros, Thomas (1999), Giles (1999), Schneider e Enste (2000) e Schneider e Klingmair (2004). O presente artigo se limitará a descrever o Modelo Dinâmico de Múltiplas Causas e Múltiplos Indicadores (DYMIMIC), que foi utilizado por Schneider (2004) para obtenção das estimativas utilizadas aqui. O método DYMIMIC foi desenvolvido a partir da teoria estatística de variáveis não-observáveis, que considera simultaneamente os determinantes e os efeitos do fenômeno a ser mensurado.

Assume-se que as seguintes variáveis afetam o tamanho do setor informal: o peso da carga tributária, as restrições impostas pela regulação e a disposição dos indivíduos de atuarem na informalidade. A economia informal, por sua vez, se faz sentir: (i) na quantidade de transações monetárias, já que a remuneração e os dispêndios das atividades informais ocorrem normalmente em forma de papel-moeda; (ii) na taxa de participação da mão-de-obra e no número de horas trabalhadas na economia formal, que tendem a declinar com o aumento da informalidade; e (iii) na saída de insumos da economia formal, impactando negativamente na taxa oficial de crescimento econômico de um país. As seguintes equações estruturais são, então, estimadas: 


$$
\left\{\begin{array}{l}
I=\alpha X+\varepsilon_{1} \\
Y=\beta I+\varepsilon_{2}
\end{array}\right.
$$

onde $I$ representa a economia informal (a variável não-observável), $X$ é uma matriz com as variáveis representando as causas da economia informal, $Y$ representa os indicadores afetados pela economia informal e $\varepsilon_{1}$ e $\varepsilon_{2}$ são termos aleatórios, distribuidos independentemente, com média zero, co-variância constante e não são correlacionados entre si.

O modelo DYMIMIC, no entanto, permite apenas a derivação de um número índice representando a produção da economia informal. Para se converter este índice em percentual do PIB, Schneider (2004) estimou em separado um modelo de demanda por moeda. Este modelo assume que transações no setor informal normalmente envolvem o uso de papel-moeda para evitar a identificação por parte de entidades governamentais. Estimativas do tamanho médio da economia informal no longo prazo são obtidas através de uma análise de regressão, em que se objetiva isolar o excesso de demanda por moeda resultante de aumentos na informalidade. A análise de regressão inclui a demanda por moeda como variável dependente e o nível de renda, hábitos de pagamento e taxas de juros como variáveis independentes. Variáveis independentes adicionais são incluídas, como o peso da carga tributária e da regulação e a complexidade do sistema fiscal, que são considerados fatores importantes na decisão dos indivíduos de optarem pela informalidade.

Estima-se, então, o comportamento da demanda por moeda em duas situações: quando o peso da carga tributária e da regulação e a complexidade do sistema fiscal são reduzidos ou quando essas variáveis são elevadas. Atribui-se esta diferença na demanda por moeda como aquela advinda do setor informal. Com base nesta análise do comportamento da demanda por moeda, Schneider (2004) utilizou valores diferenciados para a velocidade de circulação da moeda para estimar o tamanho médio da economia informal no longo prazo. Esta medida foi então combinada com o índice obtido no modelo DYMIMIC para a obtenção do percentual do PIB representando a economia informal de um país.

O modelo DYMIMIC tem sido utilizado extensivamente na literatura para a obtenção de estimativas da magnitude do setor informal de diversos países. No Brasil, tal procedimento foi adotado por Ribeiro e Bugarin (2003), que apontam o peso da carga tributária, o grau de regulamentação da economia e a taxa de desemprego como os principais determinantes da economia informal no País. 


\subsection{Variápeis Instrumentais}

A evidência empírica sugere que países com taxas de crescimento econômico mais elevado apresentam flutuaçóes menos acentuadas nas atividades econômicas e um setor informal menos expressivo. Os testes conduzidos no presente trabalho utilizaram variáveis instrumentais diversas para controlar a possibilidade de que a volatilidade dos ciclos econômicos e o tamanho da economia informal sejam variáveis endógenas.

Trabalhos empíricos sobre os determinantes do setor informal apontam para algumas variáveis que parecem influenciar o tamanho da economia informal (ver Johnson, Kaufmann e Zoido-Lobaton, 1998 e 1999; Schneider e Enste, 2000; Friedman et al., 2000; Farrell, 2004). De uma forma geral, três fatores contribuem para a informalidade: impunidade quando obrigações legais não são cumpridas, elevados custos de operação no setor formal e normas sociais. Quando as obrigações legais podem ser facilmente evitadas, os custos de operação no mercado informal são menores em face da reduzida probabilidade de detecção e instauração de processo criminal. O peso da carga tributária, a rigidez na legislação trabalhista, os custos com a burocracia e o alto nível de corrupção também estimulam a entrada de empresas na informalidade e geram um "círculo vicioso": os altos custos de se operar formalmente levam mais empresas à informalidade, reduzindo as receitas governamentais, a qualidade dos serviços públicos, e, conseqüentemente, os incentivos para que as empresas operem formalmente. Finalmente, em muitos países, a evasão de impostos e o desrespeito às leis são considerados direitos legítimos de pequenas empresas que competem com grandes empreendedores.

O presente trabalho utilizou as seguintes variáveis instrumentais: ${ }^{8}$

- Tradição Legal (TRADLEG): essa variável mede a tradição de cada país no que se refere a preceitos legais e de ordem; ou seja, mede o nível de confiança e respeito que os indivíduos têm para com a regulação. Este índice, que corresponde ao ano de 1996, varia entre -2.5 e 2.5 , com os valores menores refletindo a impunidade para com o descumprimento de obrigações legais.

- Corrupção (CORRUPÇÃO): esta variável é uma estimativa do nível em que agentes governamentais utilizam-se do seu poder político para ganho privado. O índice de corrupção tem por objetivo capturar o fato de que, apesar das empresas poderem até estar dispostas a pagar taxas de impostos em níveis razoáveis, elas optam pela informalidade a fim de evitar as demandas extorsivas e arbitrárias de

8 Procurou-se utilizar valores das variáveis instrumentais para o ano de 1996 ou 1997, pois o impacto das variáveis instrumentais sobre INFORMAL não ocorre imediatamente. Ou seja, espera-se que mudanças em INFORMAL em um período " $t$ " sejam influenciadas pelo nível das variáveis instrumentais em " $t$ $-n$ ”, onde $n=3$ ou 4 (dependendo da disponibilidade de dados estatísticos). 
órgãos fiscalizadores do Estado. $\mathrm{O}$ índice, que também corresponde ao ano de 1996, varia entre -2.5 e 2.5 , com os valores menores representando um maior nível de corrupção.

- Legislação Trabalhista (EMPIND): este indicador engloba informação sobre três aspectos diferentes da legislação trabalhista: a flexibilidade com que as empresas contratam trabalhadores, a flexibilidade com que elas demitem trabalhadores e as condiçóes de emprego. Maiores valores para este índice implicam maior proteção para os trabalhadores empregados, ou seja, maior custo a ser incorrido pelas empresas caso desejem desviar de um hipotético contrato de trabalho rígido em que os trabalhadores não podem ser demitidos. A informação contida neste índice refere-se ao ano de 1997. ${ }^{9}$

- Taxa de Imposto de Renda (IMPRENDA): este índice varia entre 1 e 10, com os valores menores refletindo maiores taxas marginais de imposto para um determinado nível de renda. A informação contida neste índice é para o ano de 1997.

- Política Fiscal (POLFISC): esta variável mede a situação fiscal do governo de uma maneira mais geral, levando em conta o nível das taxas de imposto de renda e de capital e os gastos do governo em relação ao PIB. Este índice, que contém informação para o ano de 1997, varia entre 1 e 5, com os valores maiores refletindo uma posição fiscal mais desfavorável.

As primeiras duas variáveis foram obtidas do banco de dados Governance Indicators Database (2002) elaborado pelo Banco Mundial; a terceira variável foi obtida no banco de dados Doing Business Database (2003), também desenvolvido pelo Banco Mundial; a quarta variável foi obtida da publicação Economic Freedom of the World (1999), elaborada pelo Fraser Institute; e a quinta variável teve por fonte o Index of Economic Freedom (2003) da Heritage Foundation. Como essas variáveis estão relacionadas com a origem legal de cada país, elas podem ser consideradas exógenas, pois o sistema legal da maioria dos países foi estabelecido através da colonização ou por cópia direta ou mais subjetiva (ver La Porta $e t$ al, 1998 e Botero et al, 2004).

A Tabela $\mathrm{l}$ apresenta os resultados da análise de regressão simples dos determinantes do tamanho da economia informal. Como TRADLEG e CORRUPÇÃO possuem um elevado índice de correlação entre si, cada variável foi incluída separadamente nas equações estimadas, a fim de se evitar problemas associados à multicolinearidade. Assim como indicado por Johnson, Kaufmann e Zoido-Lobaton (1998, 1999) e Friedman et al. (2000), a fraca tradição de cumprimento de preceitos legais e de

9 Para uma descrição detalhada de como este índice foi calculado, ver Botero, Djankov, La Porta et al (2004). 
ordem e a corrupção em larga escala são as principais razões que levam empresas à informalidade: TRADLEG e CORRUPÇÃO são estatisticamente significantes a um nível de $1 \%$. Salienta-se, ainda, o resultado surpreendente de que o tamanho do setor informal é negativamente correlacionado com o peso da carga tributária, resultado este também encontrado pelos referidos autores.

Os resultados discutidos abaixo têm por foco as regressões utilizando TRADLEG e CORRUPÇÃO como variáveis instrumentais. O uso de variáveis instrumentais alternativas e seu impacto sobre os resultados obtidos serão discutidos na seção que considera a robustez dos testes empíricos realizados.

TABELA 1 - DETERMINANTES DA ECONOMIA INFORMAL: ANÁLISE DE REGRESSÃO

\begin{tabular}{lcc|cc}
\hline & \multicolumn{2}{c|}{$1961-2002$} & \multicolumn{2}{c}{$1985-2002$} \\
\hline C & $44,350^{* * *}$ & $44,614^{* * *}$ & $45,904^{* * *}$ & $50,178^{* * *}$ \\
TRADLEG & $(3,683)$ & $(3,423)$ & $(3,409)$ & $(4,186)$ \\
& $-9,621^{* * *}$ & & $-9,353^{* * *}$ & \\
CORRUPÇÃO & $(-6,649)$ & $(-7,270)$ & $-8,102^{* * *}$ \\
& & & & $(-7,920)$ \\
EMPIND & & $-7,814^{* * *}$ & & 2,038 \\
& 1,105 & $(-6,432)$ & 2,117 & $(1,046)$ \\
IMPRENDA & $(0,450)$ & $(0,647)$ & $(0,951)$ & 0,013 \\
& 0,085 & 0,202 & 0,146 & $(0,027)$ \\
POLIFISC & $(0,132)$ & $(0,292)$ & $(0,265)$ & $-5,262^{* *}$ \\
& $-3,096$ & $-3,960^{*}$ & $-4,021$ & $(-2,079)$ \\
\hline No. Obs. & $(-1,437)$ & $(-1,793)$ & $(-1,482)$ & 45 \\
$R^{2}$ (Ajustado) & 42 & 42 & 45 & 0,662 \\
\hline
\end{tabular}

Notas: (1) Método dos mínimos quadrados ordinários; (2) Desvio padrão e co-variância são consistentes em relação à presença de heterocedasticidade (método White).

\subsection{Variáveis de Controle}

Várias variáveis de controle foram incluídas nos testes econométricos com o intuito de se mensurar a importância de outros determinantes da volatilidade dos ciclos econômicos. Foram inclusos dois indicadores de desenvolvimento do sistema financeiro, o resíduo de Solow, a taxa de inflação, os gastos fiscais do governo, o grau de abertura para o comércio internacional e a volatilidade da taxa cambial. A mediana dessas variáveis foi calculada para os períodos 1961-2002 e 1985-2002, com exceção da taxa de inflação e do resíduo de Solow: foi utilizada a taxa de inflação média e o desvio 
padrão do componente do resíduo de Solow que representa os ciclos econômicos em cada período.

Estudos empíricos recentes demonstram que um maior desenvolvimento do sistema financeiro contribui para a redução da volatilidade dos ciclos econômicos (ver Denizer, Iyigun e Owen, 2002 e Ferreira da Silva, 2002). Quando as instituições financeiras tornam-se mais eficientes na avaliação de propostas de crédito, a probabilidade de que um projeto sem solidez financeira seja financiado com recursos de terceiros diminui, trazendo flutuações econômicas menos acentuadas. Apesar das dificuldades em se estimar precisamente a eficiência com que as instituições financeiras selecionam e monitoram seus clientes, dois indicadores de desenvolvimento foram utilizados aqui: ${ }^{10}$

- LLY: esta variável mede a representatividade do setor financeiro formal e é calculada através da divisão do passivo líquido de um país pelo seu PIB. Assume-se aqui que, quanto mais eficiente e, portanto, mais lucrativo for o setor financeiro, um maior fluxo de recursos será por este absorvido e maior será o valor deste indicador.

- CREDPRIV: esta variável representa o percentual do volume de crédito doméstico total que é direcionado para o setor privado. Neste caso, considera-se que sistemas financeiros que direcionam crédito para o setor privado tendem a ser mais eficientes no processo de seleção e monitoramento do que sistemas financeiros que alocam um percentual maior de seus recursos para empresas públicas (empréstimos concedidos a empresas governamentais são feitos, muitas vezes, sob hipótese de que o governo garantirá o pagamento em última instância, o que implica menor necessidade de se implementar um processo minucioso de seleção e monitoramento).

Os precursores da teoria dos Ciclos Econômicos Reais (Real Business Cycles) enfatizam a importância dos choques tecnológicos como determinantes das flutuações na atividade econômica. Estes choques são representados pela volatilidade do resíduo de Solow $\left(\sigma_{\text {solow }}\right)$, que é calculado pela variação no log do PIB entre dois períodos menos (1- $\left.\alpha\right)$ multiplicado pela variação no log do volume de emprego entre dois períodos, sendo $\alpha$ a fração do capital sobre o produto $\left(\alpha=0.36\right.$, por definição). ${ }^{11}$ Note que, ao utilizar este método de estimativa dos choques tecnológicos, ignora-se a possibilidade de que

10 Os indicadores de desenvolvimento financeiro são baseados no trabalho de King e Levine (1993). Estes autores propõem o uso de dois indicadores adicionais, mas as variáveis utilizadas aqui são consideradas mais apropriadas para representar o desenvolvimento do mercado financeiro (ver o artigo em questão para obter maiores detalhes sobre o cálculo desses indicadores). As regressões foram implementadas com estes indicadores adicionais e os resultados encontrados foram similares aos descritos a seguir (estes resultados adicionais estão à disposição caso sejam solicitados).

11 Ou seja, Resíduo de Solow ${ }_{t}=\left(\log R P I B_{t}-\log R P I B_{t-1}\right)-(1-\alpha)\left(\log N_{t}-\log N_{t-1}\right)$, onde RPIB é o produto interno bruto em termos reais, $N$ é o número de trabalhadores empregados e $t$ representa a unidade de tempo. 
(i) o resíduo esteja capturando mais do que somente os choques tecnológicos; ${ }^{12}$ (ii) alguns países podem não ter uma função de produção do tipo Cobb-Douglas com retornos constantes de escala; e (iii) alguns países possam ter frações de capital distintas. Mais ainda, este cálculo não leva em consideração o valor de $\alpha$ multiplicado pela mudança no estoque de capital entre dois períodos - Backus, Kehoe e Kydland (1992) demonstram que tal exclusão não causa problemas significativos. Apesar dessas ressalvas, a dificuldade na obtenção de informações mais acuradas faz com que métodos alternativos não sejam viáveis no presente momento. ${ }^{13}$

Duas variáveis foram utilizadas para medir o impacto de políticas monetária e fiscal sobre os ciclos econômicos. A taxa de inflação média (MPOL) foi utilizada para representar o grau de flexibilização da política monetária, enquanto o percentual de despesa de consumo do governo em relação ao PIB (GOV) capturou o efeito da política fiscal sobre a volatilidade das flutuações econômicas.

O comércio internacional e a política cambial também são comumente associados à volatilidade dos ciclos econômicos. A abertura ao comércio internacional pode ampliar ou reduzir essa volatilidade: economias com menores barreiras ao comércio exterior são mais vulneráveis a choques originados no mercado internacional, mas são, por outro lado, mais capazes de minimizar o impacto de choques domésticos, exportando-os. COMINTL foi calculado como a divisão entre o comércio total - a soma das exportações com as importações - e o PIB. O impacto da política cambial sobre as flutuações econômicas, por sua vez, também é ambíguo, visto que regimes com taxas de câmbio fixas ou flexíveis responderão de forma diferenciada a choques de origem fiscal ou monetária. O grau de flexibilidade da política cambial é representado por CAMBFLEX, variável calculada como o valor absoluto da variação na taxa de câmbio entre dois períodos (a taxa de câmbio foi calculada como o valor dos Direitos Especiais de Saque do Fundo Monetário Internacional, por unidade de moeda nacional).

Finalmente, Ramey e Ramey (1994) indicam que existe uma relação negativa e estatisticamente significante entre a volatilidade dos ciclos econômicos e o crescimento econômico de longo prazo. LPCRES é estimado como a taxa de crescimento do componente de tendência (trend component) do log do PIB per capita em termos reais.

Apesar de as variáveis de controle serem consideradas exógenas nos testes descritos abaixo, elas são provavelmente endógenas. A estratégia de assumir a exogeneidade das

12 Hall (1989) e Hall e Jones (1998) salientam que o resíduo de Solow pode estar capturando outros determinantes de produtividade, como a qualidade do capital humano, treinamento (learning by doing) e efeitos temporais.

13 A dificuldade em se encontrar dados estatísticos para calcular o resíduo de Solow - mais especificamente, séries históricas do nível de emprego - é o principal motivo pelo qual foi necessário restringir o número de países incluídos nos testes. Quando a informação não estava disponível no IFS para certos períodos, dados adicionais foram obtidos de agências governamentais. 
variáveis de controle implica que os coeficientes estimados dessas variáveis apresentam valores acima do correto, enquanto o coeficiente de INFORMAL é subestimado. Ou seja, tratar as variáveis de controle como exógenas é uma estratégia "conservadora", pois implica a redução da probabilidade de se encontrar um papel relevante para a variável INFORMAL, enquanto aumenta-se a possibilidade de se encontrar um papel substancial para as variáveis de controle (ver Acemoglu et al., 2003).

\section{METODOLOGIA}

Os testes econométricos foram implementados em duas amostras separadas de dados estatísticos em formato de cross-section: na amostra completa, cada país possui uma observação para cada variável para o período entre 1961 e 2002, enquanto, na amostra menor, as variáveis foram calculadas levando-se em consideração o período entre 1985 e 2002. A decisão de implementar os testes em duas amostras diferentes decorre do fato de que dados estatísticos para o tamanho do setor informal existem somente para $1999 / 2000$ e $2001 / 2002$.

Poderia-se argumentar que uma associação entre o tamanho da economia informal e a volatilidade dos ciclos econômicos para a amostra completa não seria apropriada. No entanto, para se calcular a volatilidade dos ciclos econômicos, é necessário ter um número razoável de observações nas séries temporais. Por conseqüência, os testes foram implementados em uma segunda amostra, que é curta o suficiente para estabelecer a conexão pretendida entre a economia informal e os ciclos econômicos, mas longa o suficiente para permitir o cálculo da volatilidade dos ciclos econômicos.

As flutuações na atividade econômica são representadas pelo desvio padrão do componente das séries PIB real, investimento real e consumo privado real que representa o ciclo econômico. ${ }^{14}$ Portanto, antes de fazer a análise de regressão, é necessário separar os diversos componentes destas séries e do resíduo de Solow: o componente sazonal, o componente de tendência (representando o crescimento de longo prazo) e o componente representando as variações durante o ciclo econômico. Foi utilizado um filtro (band-pass filter) desenvolvido por Baxter e King (1999) para isolar o componente que representa os ciclos econômicos de cada uma das referidas variáveis, conforme estudos empíricos recentes sobre ciclos econômicos (ver, por exemplo, Stock e Watson, 1998; e Basu e Taylor, 1999).

Filtros do tipo band-pass são modelos de médias móveis (moving-averages) desenhados de forma que o pesquisador possa determinar ex-ante as periodicidades dos ciclos

14 As expressões "a volatilidade do componente representando o ciclo econômico" e "a volatilidade" de uma série são utilizadas como sinônimos no presente contexto. 
econômicos, eliminando os componentes das séries cujas freqüências localizam-se fora de um intervalo pré-especificado. Este filtro possui as seguintes vantagens em relação a metodologias alternativas, como linear detrending, diferenciação de primeiro grau ou o filtro de Hodrik-Prescott (ver Baxter e King, 1999): (i) remove raízes unitárias, tornando a série estacionária; (ii) não altera a relação temporal das variáveis; (iii) isola as freqüências dos ciclos econômicos sem determinar pesos para os componentes; (iv) constitui uma aproximação ótima de um filtro tipo band-pass ideal; e (v) gera componentes de ciclos econômicos que são independentes do tamanho do período da amostra.

A metodologia econométrica utilizada foi o Generalized Method of Moments (GMM). $\mathrm{Na}$ presença de heterocedasticidade, que é comum em análise de regressão com dados em cross-section, GMM é mais eficiente do que o método dos Mínimos Quadrados em Dois Estágios (2SLS). Mais ainda, GMM permite o teste de validade dos instrumentos utilizados.

As equações estimadas possuem o seguinte formato:

$$
\sigma_{\mathrm{m}}=\beta_{1}+\beta_{2} I N F O R M A L+\beta_{3} X+\varepsilon
$$

onde $\sigma_{\mathrm{m}}$ representa a volatilidade do componente das séries produção, investimento e consumo que representa os ciclos econômicos; e $X$ é uma matriz de informação condicional que permite levar em consideração outros determinantes da volatilidade dos ciclos econômicos (esta matriz inclui um indicador de desenvolvimento financeiro de cada vez, além de todas as outras variáveis de controle). Os resultados apresentados a seguir são aqueles em que os instrumentos incluem TRADLEG, CORRUPÇÃO e a matriz $X$.

\section{RESULTADOS}

Os testes empíricos discutidos nesta seção indicam que países com economia informal expressiva tendem a experimentar flutuações mais acentuadas na atividade econômica e os resultados são mais robustos estaticamente nas análises de regressão conduzidas com a amostra completa.

Um outro aspecto interessante dos resultados apresentados a seguir é a falta de importância de outros fatores que são normalmente considerados relevantes na determinação da volatilidade dos ciclos econômicos. A maioria das variáveis de controle perde importância quando a variável representando o tamanho da economia informal 
é adicionada na análise de regressão. Uma possível explicação para tal resultado seria a existência de relação linear entre as variáveis independentes, mas cálculos dos fatores de inflação da variância (variance inflated factors ou VIF) não indicam a presença de multicolinearidade. ${ }^{15}$

É importante salientar que os resultados indicam que o componente exógeno do tamanho da economia informal, que é determinado, por sua vez, pelas variáveis instrumentais, é relevante na determinação da volatilidade dos ciclos econômicos. Como as variáveis instrumentais refletem as características institucionais de um país, a irrelevância das variáveis de controle é um resultado em sintonia com o trabalho de Acemoglu et al. (2003): esses autores demonstraram que variáveis macroeconômicas tendem a demonstrar um menor impacto sobre a volatilidade econômica tão logo se leve em consideração a influência das instituições. Portanto, a economia informal parece ser um canal através do qual instituições afetam a volatilidade dos ciclos econômicos.

\subsection{Amostra Completa: $1961-2002$}

Os resultados obtidos com a amostra para o período mais prolongado indicam que países com uma economia informal significativa experimentam maior volatilidade no componente da produção referente aos ciclos econômicos (Tabela 2a). INFORMAL é estatisticamente significante a um nível de 1\% nas análises de regressão em que a volatilidade no PIB representa a variável dependente, qualquer que seja o indicador de desenvolvimento do sistema financeiro utilizado. Como exemplo da relevância de INFORMAL, considere o caso da Índia, cuja volatilidade na produção de 0.019 representa a mediana da amostra. Se o tamanho da economia informal na Índia crescesse $10 \%$ - de 23,65\% do PIB do país para 26,02\% -, a volatilidade da produção cresceria 12,4\%. Além da variável INFORMAL, somente o resíduo de Solow é estatisticamente relevante para a volatilidade da produção, com um coeficiente positivo e um nível de significância de pelo menos $5 \%$.

O tamanho da economia informal é também estatisticamente significante na análise de regressão em que o investimento é a variável dependente (Tabela $2 \mathrm{~b}$ ). Em termos de relevância econômica, um aumento de 10\% no tamanho do setor informal da Finlândia, país cuja volatilidade no investimento de 0.063 representa a mediana da amostra, levaria a um incremento na volatilidade do investimento de 5,7\%. Dentre as variáveis de controle, apenas COMINTL e CAMBFLEX são estatisticamente relevantes para a volatilidade no componente da série de investimento representando os ciclos econômicos: países com maior abertura comercial e com taxas de câmbio mais

15 Todos os VIFs situaram-se abaixo de 1,5 , quando apenas valores acima de 2,5 podem indicar a presença de multicolinearidade. As análises de regressão utilizadas para o cálculos dos VIFs encontram-se à disposição, caso sejam solicitadas. 
flexíveis tendem a apresentar maior volatilidade no investimento. Note, no entanto, que enquanto COMINTL é significante a um nível de pelo menos 5\%, CAMBFLEX apresenta relevância estatística de apenas $10 \%$.

A importância do tamanho do setor informal de um país para as flutuações na atividade econômica também é ilustrada quando a volatilidade do consumo privado é a variável dependente na análise de regressão: INFORMAL é estatisticamente significante a um nível de pelo menos $5 \%$ (Tabela 2 c). Neste caso, um aumento do escopo da economia informal em $10 \%$ na Coréia do Sul, cuja volatilidade do consumo representa a mediana da amostra, a volatilidade do componente do consumo privado que representa os ciclos econômicos cresce 10,7\%. Com exceção de COMINTL, que é positivamente correlacionada com a volatilidade do consumo e estatisticamente significante a um nível de pelo menos $5 \%$, nenhuma outra variável de controle apresenta expressividade em termos estatísticos. 
TABELA 2 - FLUTUAÇÕES NA ATIVIDADE ECONÔMICA, 1961 - 2002

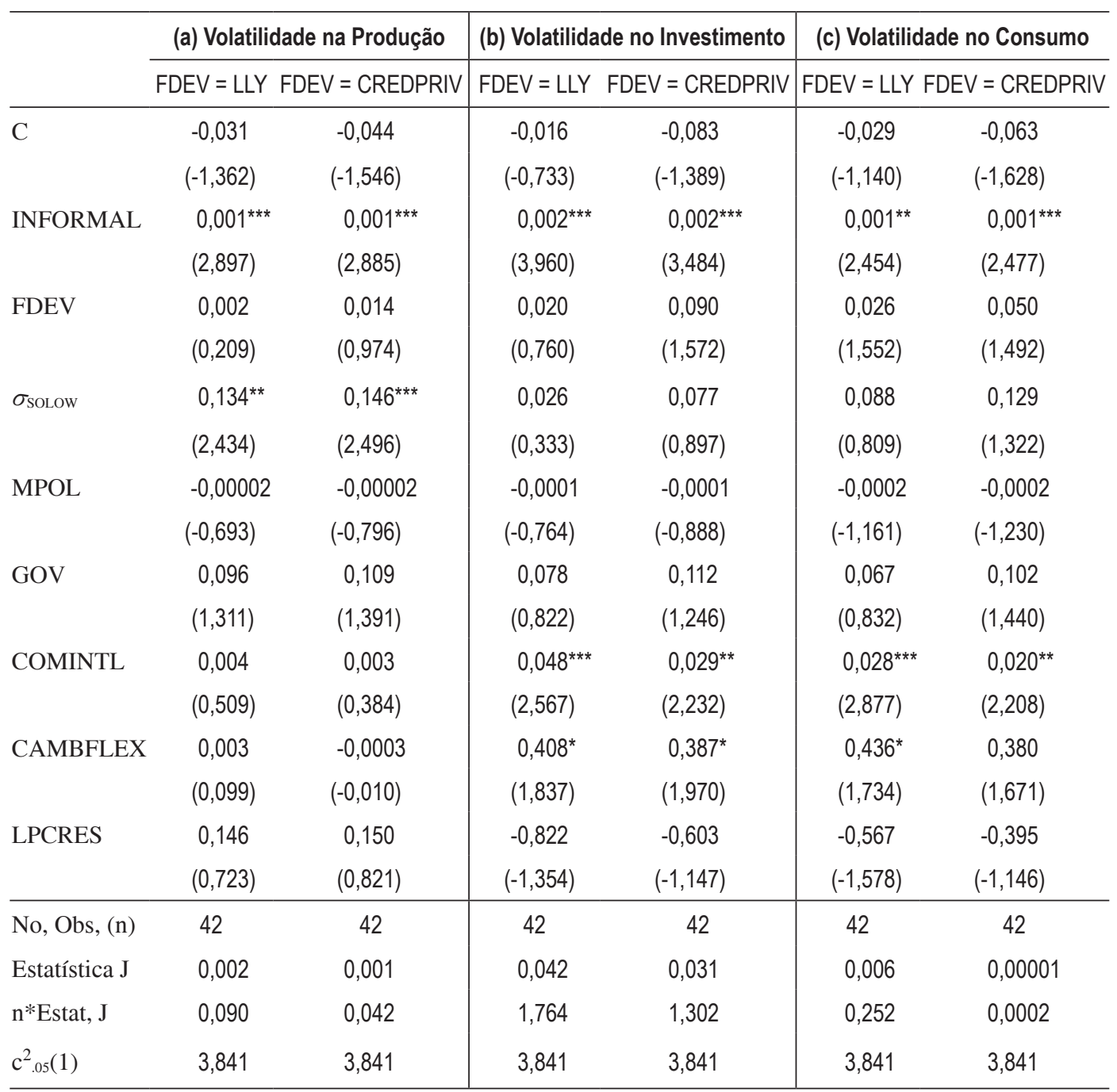

Notas: (1) Números entre parêntesis representam as estatísticas $t ;{ }^{*},{ }^{* *} \mathrm{e}^{* * *}$ indicam níveis de significância de $10 \%, 5 \%$ e $1 \%$; (2) Matriz de Ponderação: os valores estimados quando utilizamos o GMM são robustos no que se refere a heterocedasticidade de fonte desconhecida; (3) Instrumentos: Conjunto de informaçôes condicionantes mais os índices TRADLEG e CORRUPÇÃO.

No caso do Brasil, o impacto da economia informal sobre as flutuações na atividade econômica também é considerável. Um aumento de $10 \%$ no tamanho do setor informal do País - de 40,35\% para 44,39\% do PIB - levaria a um aumento de 16,1\% na volatilidade do PIB, de 5,3\% na volatilidade do investimento e de $6,1 \%$ na volatilidade do consumo. Portanto, a falta de produtividade e a incapacidade da economia informal de suavizar as flutuações no fluxo de caixa contribuem tanto para um menor crescimento econômico, como indicado por Mckinsey \& Company (2004), quanto 
para uma volatilidade maior nos ciclos econômicos do país. Os resultados empíricos apresentados neste trabalho apontam para a necessidade de se promover instituiçóes que estimulem empresas a manterem-se na formalidade, como o respeito à lei e à ordem, um menor nível de corrupção, a redução de encargos tributários e uma legislação trabalhista menos rígida. O Brasil, de acordo com dados do Banco Mundial (2003), ocupa a $144^{\mathrm{a}}$ posição, entre 155 países, no que se refere à rigidez no mercado de trabalho e a $140^{a}$ posição no que se refere ao ônus tributário; também de acordo com o Banco Mundial (2002), o Brasil ocupa a 113 a posição, entre 209 países, no indicador de respeito à lei e à ordem e a $90^{a}$ posição no que se refere ao controle da corrupção. ${ }^{16}$

\subsection{Amostra Menor: 1985 - 2002}

Como salientado anteriormente, os dados estatísticos sobre o tamanho da economia informal para diversos países encontram-se disponíveis somente para os períodos $1999 / 2000$ e 2000/2001. Portanto, é possível questionar a validade de se estabelecer uma conexão entre o tamanho da economia informal e a volatilidade dos ciclos econômicos quando as variáveis dependentes e de controle referem-se a um período entre 1961 e 2002.

Com o objetivo de lidar com este problema, os testes foram refeitos utilizando-se dados estatísticos entre 1985 e 2002 . Este período é longo o suficiente para se calcular a volatilidade nos ciclos econômicos e o tamanho do setor informal neste período é, provavelmente, mais próximo dos valores disponíveis em Schneider (2004). A Tabela 3 apresenta os resultados estimados pela análise de regressão. De uma forma geral, a economia informal continua sendo estatisticamente significante para as flutuaçóes na atividade econômica. No entanto, os resultados em que FEDV é representado por LLY são menos robustos.

Considere inicialmente a volatilidade do componente da produção que representa os ciclos econômicos (Tabela 3a). Quando LLY é utilizado para representar o indicador de desenvolvimento financeiro, somente GOV é estatisticamente relevante (LLY é significante, mas a um nível de 10\%). No entanto, quando substituímos LLY por CREDPRIV, INFORMAL torna-se significante a um nível de 1\%. Em termos de relevância econômica, considere o caso da Irlanda, cuja volatilidade na produção no valor de 0.014 representa a mediana da amostra. Um aumento de $10 \%$ no tamanho do setor informal gera uma expansão de 4,5\% na volatilidade da produção. Na regressão em que FDEV é representado por CREDPRIV, apenas o volume de crédito

16 Os países foram ordenados de forma que os classificados nas primeiras posições possuem melhores indicadores de condições de negócios (Doing Business Database) e de governança (Governance Indicators). Dados para 2005 indicam que a performance do Brasil foi ainda mais precária. 
destinado ao setor privado é relevante para a volatilidade da produção: CREDPRIV é positivamente relacionado com a volatilidade da produção e estatisticamente significante a um nível de $1 \% .^{17}$

TABELA 3 - FLUTUAÇÕES NA ATIVIDADE ECONÔMICA, 1985 - 2002

\begin{tabular}{|c|c|c|c|c|c|c|}
\hline & \multicolumn{2}{|c|}{ (a) Volatilidade na Produção } & \multicolumn{2}{|c|}{ (b) Volatilidade no Investimento } & \multicolumn{2}{|c|}{ (c) Volatilidade no Consumo } \\
\hline & $\mathrm{FDEV}=\mathrm{LLY}$ & FDEV = CREDPRIV & FDEV $=\mathrm{LLY}$ & FDEV = CREDPRIV & FDEV $=$ LLY & FDEV $=$ CREDPRIV \\
\hline \multirow[t]{2}{*}{$\mathrm{C}$} & $0,027^{\star \star *}$ & $-0,001$ & 0,045 & $-0,019$ & 0,022 & $-0,014$ \\
\hline & $(2,490)$ & $(-0,086)$ & $(1,306)$ & $(-0,581)$ & $(1,404)$ & $(-0,793)$ \\
\hline \multirow{2}{*}{$\begin{array}{l}\text { INFOR- } \\
\text { MAL }\end{array}$} & 0,0001 & $0,0004^{* * *}$ & $0,001^{*}$ & $0,002^{* * *}$ & 0,0003 & $0,001^{* *}$ \\
\hline & $(0,360)$ & $(2,474)$ & $(2,039)$ & $(4,444)$ & $(1,107)$ & $(2,394)$ \\
\hline \multirow[t]{2}{*}{ FDEV } & $-0,012^{*}$ & $0,019^{* * *}$ & $-0,022$ & $0,042^{* *}$ & $-0,014$ & $0,023^{* *}$ \\
\hline & $(-1,926)$ & $(3,057)$ & $(-1,277)$ & $(2,379)$ & $(-1,570)$ & $(2,224)$ \\
\hline \multirow[t]{2}{*}{$\sigma_{\text {SOLOW }}$} & $-0,018$ & $-0,126$ & $-0,139$ & $-0,459^{\star * *}$ & $-0,107$ & $-0,210^{*}$ \\
\hline & $(-0,281)$ & $(-1,549)$ & $(-0,804)$ & $(-2,793)$ & $(-1,139)$ & $(-1,851)$ \\
\hline \multirow[t]{2}{*}{ MPOL } & 0,000002 & $-0,00001$ & 0,00001 & $-0,00002$ & 0,00003 & 0,00002 \\
\hline & $(0,102)$ & $(-0,418)$ & $(0,337)$ & $(-0,308)$ & $(1,932)$ & $(0,825)$ \\
\hline \multirow[t]{2}{*}{ GOV } & $-0,051^{* \star}$ & $-0,034$ & $-0,068$ & $-0,017$ & $-0,031$ & $-0,006$ \\
\hline & $(-2,328)$ & $(-1,438)$ & $(-0,971)$ & $(-0,228)$ & $(-0,936)$ & $(-0,160)$ \\
\hline \multirow[t]{2}{*}{ COMINTL } & 0,003 & $-0,002$ & 0,020 & 0,010 & 0,009 & 0,002 \\
\hline & $(0,797)$ & $(-0,724)$ & $(1,304)$ & $(0,670)$ & $(1,580)$ & $(0,315)$ \\
\hline \multirow{2}{*}{$\begin{array}{l}\text { CAMB- } \\
\text { FLEX }\end{array}$} & 0,001 & 0,012 & $-0,002$ & 0,019 & 0,008 & 0,022 \\
\hline & $(0,079)$ & $(0,602)$ & $(-0,059)$ & $(0,404)$ & $(0,422)$ & $(0,910)$ \\
\hline \multirow[t]{2}{*}{ LPCRES } & 0,103 & 0,045 & 0,111 & $-0,053$ & 0,081 & 0,078 \\
\hline & $(1,193)$ & $(0,567)$ & $(0,465)$ & $(-0,248)$ & $(0,612)$ & $(0,534)$ \\
\hline No. Obs. (n) & 45 & 45 & 45 & 45 & 45 & 45 \\
\hline Estatística J & 0,003 & 0,011 & 0,033 & 0,056 & 0,016 & 0,022 \\
\hline $\mathrm{n} *$ Estat. J & 0,135 & 0,495 & 1,485 & 2,520 & 0,720 & 0,990 \\
\hline $\mathrm{c}^{2} .05(1)$ & 3,841 & 3,841 & 3,841 & 3,841 & 3,841 & 3,841 \\
\hline
\end{tabular}

Notas: (1) Números entre parêntesis representam as estatísticas $t$; ${ }^{*},{ }^{*} \mathrm{e}^{* * *}$ indicam níveis de significância de $10 \%, 5 \%$ e $1 \%$; (2) Matriz de Ponderação: os valores estimados quando utilizamos o GMM são robustos no que se refere a heterocedasticidade de fonte desconhecida; (3) Instrumentos: Conjunto de informações condicionantes mais os índices TRADLEG e CORRUPÇÃO.

Os resultados das regressões em que a volatilidade do investimento é a variável dependente estão dispostos na Tabela 3b. Neste caso, INFORMAL é estatisticamente signi-

17 A obtenção de uma correlação positiva entre CREDPRIV e volatilidade dos ciclos econômicos difere de resultados apresentados por outros autores (ver Denizer, Iyigun e Owen, 2002 e Ferreira da Silva, 2002) e indica que o acesso ao crédito permite que os agentes econômicos se comportem como sugerido por Minsky (1986). Ou seja, quando a economia se aproxima da fase de pico do ciclo econômico, existe uma probabilidade maior de que esquemas especulativos ou do tipo Ponzi se concretizem. Desde que existam instituições financeiras para financiar estes esquemas, o comportamento "agressivo" dos agentes econômicos pode acarretar maior volatilidade nos ciclos econômicos. 
ficante a um nível de $10 \%$ quando LLY representa o índice de desenvolvimento financeiro e $1 \%$ quando CREDPRIV é utilizado como FDEV. Além de estatisticamente significante, INFORMAL é também economicamente relevante na determinação da volatilidade do investimento: um aumento de $10 \%$ no escopo da economia informal do México - país cuja volatilidade do investimento é igual à mediana da amostra - eleva a volatilidade do investimento em pelo menos $4,7 \%$ e um máximo de $9,4 \%$ (regressão em que FDEV é representado por LLY e CREDPRIV, respectivamente). No que se refere às variáveis de controle, apenas duas delas são estatisticamente significantes, ambas na regressão em que CREDPRIV representa o desenvolvimento financeiro: CREDPRIV e o resíduo de Solow são positivamente correlacionados com a volatilidade do componente do investimento que representa os ciclos econômicos e significantes do ponto de vista estatístico a níveis de $5 \%$ e $1 \%$, respectivamente.

A Tabela $3 \mathrm{c}$ apresenta os resultados obtidos quando a volatilidade no consumo representa a variável dependente. O coeficiente de INFORMAL é estatisticamente significante a um nível de 5\% quando CREDPRIV é utilizado como indicador de desenvolvimento financeiro, mas não apresenta relevância estatística quando FDEV é representado por LLY. Como um exemplo do impacto do setor informal sobre a volatilidade do consumo, considere o caso de Honduras, cuja volatilidade do consumo de 0.022 representa a mediana da amostra. Se o setor informal de Honduras crescesse $10 \%$, a volatilidade do consumo cresceria $22,8 \%$. De maneira similar aos resultados obtidos quando a volatilidade do investimento representava a variável dependente, CREDPRIV e o resíduo de Solow são as únicas variáveis de controle que contribuem para a volatilidade do consumo de uma maneira relevante: ambas são positivamente correlacionadas com a volatilidade do componente do consumo privado que representa os ciclos econômicos e significantes do ponto de vista estatístico a níveis de $5 \%$ e $10 \%$, respectivamente.

Também nesta amostra, o impacto do tamanho da economia informal sobre as flutuações econômicas no Brasil é representativo. Uma expansão de 10\% no setor informal levaria a um aumento em $10,1 \%$ na volatilidade do PIB, em 9,3\% na volatilidade do investimento e em $8,8 \%$ na volatilidade do consumo privado.

\section{ROBUSTEZ DOS RESULTADOS}

A análise da J-statistic constitui o primeiro teste de solidez dos resultados obtidos com a metodologia GMM. Em todas as regressões, os valores desta estatística foram multiplicados pelo número de observações e comparados com o valor de tabela da distribuição $\chi^{2}$ com "graus de liberdade" iguais ao número de restrições sobreidenti- 
ficadas. Em todos os casos, as variáveis instrumentais escolhidas foram consideradas informativas (significância estatística de pelo menos 5\%).

A fim de verificar a robustez dos resultados discutidos na seção anterior, foram implementadas várias estratégias. Os testes foram conduzidos utilizando-se metodologias alternativas, variáveis instrumentais diferentes e excluindo outliers. De maneira geral, a dimensão do setor informal mantém-se estatisticamente significante, independentemente da estratégia implementada.

Além de utilizar a metodologia GMM, todas as regressões foram implementadas fazendo uso do método 2SLS, incluindo os testes de solidez dos resultados (ou seja, utilizando-se variáveis instrumentais alternativas e excluindo outliers). Em todos os casos, quanto maior o tamanho da economia informal, maior a volatilidade na produção, investimento e consumo. Os resultados obtidos com o uso do método 2SLS foram similares àqueles obtidos com a metodologia GMM e, em alguns casos, com significância estatística ainda maior.

Além de TRADLEG e CORRUPÇÃO, as seguintes variáveis instrumentais também foram utilizadas nos testes: EMPIND, IMPRENDA e POLFISC. Os testes com instrumentos alternativos foram implementados de duas formas. Primeiramente, cada um dos instrumentos alternativos foi adicionado ao modelo original de regressão, juntamente com TRADLEG e CORRUPÇÃO. A decisão de utilizar até três variáveis instrumentais foi tomada levando-se em consideração que os problemas associados à performance insatisfatória em amostra finita (finite sample bias) acentuam-se com o aumento no número de instrumentos. Posteriormente, a variável CORRUPÇÃO foi substituída alternadamente por cada um dos instrumentos adicionais.

A Tabela 4 a seguir ilustra os resultados obtidos com o uso de variáveis instrumentais alternativas. ${ }^{18}$ Os números na tabela referem-se ao coeficiente de INFORMAL e sua significância estatística quando conjuntos alternativos de instrumentos são utilizados. O tamanho da economia informal mantém-se positivamente correlacionado com todas as medidas de volatilidade do ciclo econômico e, com raras exceções, seu nível de significância estatística é de pelo menos $5 \%$.

Como um teste final de solidez dos resultados, identificou-se a presença de outliers que foram excluídos da análise de regressão. A identificação dos outliers foi feita através da inspeção dos gráficos de dispersão (ver Figura 1) e confirmada com a aplicação do Teste de Grubbs. ${ }^{19}$ A exclusão dos outliers não altera significativamente os resultados:

18 Os resultados apresentados são aqueles em que CREDPRIV representa o indicador de desenvolvimento financeiro. Os resultados em que FDEV é igual a LLY são semelhantes aos resultados delineados nas Tabelas 3 e 4 e podem ser obtidos se solicitados.

19 Resultados dos testes de Grubbs encontram-se disponíveis em caso de solicitação. 
a última linha da Tabela 4 mostra que a expansão do setor informal continua a contribuir de forma significativa no aumento da volatilidade dos ciclos econômicos.

TABELA 4 - SOLIDEZ DOS RESULTADOS

\begin{tabular}{lcc|cc|cc}
\hline & \multicolumn{2}{c|}{$\begin{array}{c}\text { (a) Volatilidade na } \\
\text { Produção }\end{array}$} & $\begin{array}{c}\text { (b) Volatilidade no } \\
\text { Investimento }\end{array}$ & \multicolumn{2}{c}{$\begin{array}{c}\text { (c) Volatilidade no } \\
\text { Consumo }\end{array}$} \\
\cline { 2 - 7 } Variáveis Instrumentais: & 1961 - 2002 & $1985-2002$ & $1961-2002$ & $1985-2002$ & $1961-2002$ & $1985-2002$ \\
\hline X, RULELAW, CORRUPÇÃO, & $0,001^{* * *}$ & $0,0004^{* * *}$ & $0,002^{* * *}$ & $0,002^{* * *}$ & $0,001^{* * *}$ & $0,001^{* * *}$ \\
EMPIND & $(2,520)$ & $(2,594)$ & $(3,252)$ & $(5,569)$ & $(2,544)$ & $(2,587)$ \\
X, RULELAW, CORRUPÇÃO, & $0,001^{* * *}$ & $0,0004^{* * *}$ & $0,002^{* * *}$ & $0,002^{* * *}$ & $0,001^{*}$ & $0,001^{* * *}$ \\
TOPTAX & $(3,057)$ & $(2,503)$ & $(3,016)$ & $(4,392)$ & $(1,891)$ & $(2,208)$ \\
X, RULELAW, CORRUPÇÃO, & $0,001^{* * *}$ & $0,0004^{* * *}$ & $0,002^{* * *}$ & $0,002^{* * *}$ & $0,001^{* *}$ & $0,001^{* * *}$ \\
TAXPOL & $(3,125)$ & $(2,480)$ & $(2,997)$ & $(4,359)$ & $(2,134)$ & $(2,497)$ \\
X, RULELAW, EMPIND & 0,0005 & $0,0005^{* * *}$ & $0,003^{* * *}$ & $0,002^{* * *}$ & $0,001^{* * *}$ & $0,001^{* * *}$ \\
X, RULELAW, TOPTAX & $(1,039)$ & $(2,320)$ & $(3,384)$ & $(5,726)$ & $(3,196)$ & $(2,617)$ \\
& $0,001^{* * *}$ & $0,0005^{* * *}$ & $0,003^{* * *}$ & $0,002^{* * *}$ & $0,001^{* * *}$ & $0,001^{* * *}$ \\
X, RULELAW, TAXPOL & $(2,479)$ & $(2,323)$ & $(3,459)$ & $(4,269)$ & $(3,226)$ & $(2,503)$ \\
& $0,001^{* * *}$ & $0,0005^{* * *}$ & $0,002^{* * *}$ & $0,002^{* * *}$ & $0,001^{* *}$ & $0,001^{* * *}$ \\
& $(2,826)$ & $(2,332)$ & $(2,788)$ & $(4,513)$ & $(2,148)$ & $(2,648)$ \\
Excluindo Outliers: & & & & & & \\
\hline & $0,001^{* * *}$ & - & $0,002^{* * *}$ & - & $0,001^{* * *}$ & - \\
& $(2,166)$ & - & $(3,718)$ & - & $(2,752)$ & - \\
\hline
\end{tabular}

Notas: (1) Números entre parêntesis representam as estatísticas $t ;{ }^{*},{ }^{*} \mathrm{e}^{* * *}$ indicam níveis de significância de $10 \%, 5 \%$ e $1 \%$; (2) Matriz de Ponderação: os valores estimados quando utilizamos o GMM são robustos no que se refere a heterocedasticidade de fonte desconhecida; (3) Outliers excluídos - Coluna (a) - Quênia; Coluna (b): Uruguai e Indonésia; Coluna (c): Uruguai; (3) Não foram identificados outliers na amostra do período $1985-2002$. 
FIGURA I - IDENTIFICAÇÃO DE OUTLIERS: GRÁFICOS DE DISPERSÃO
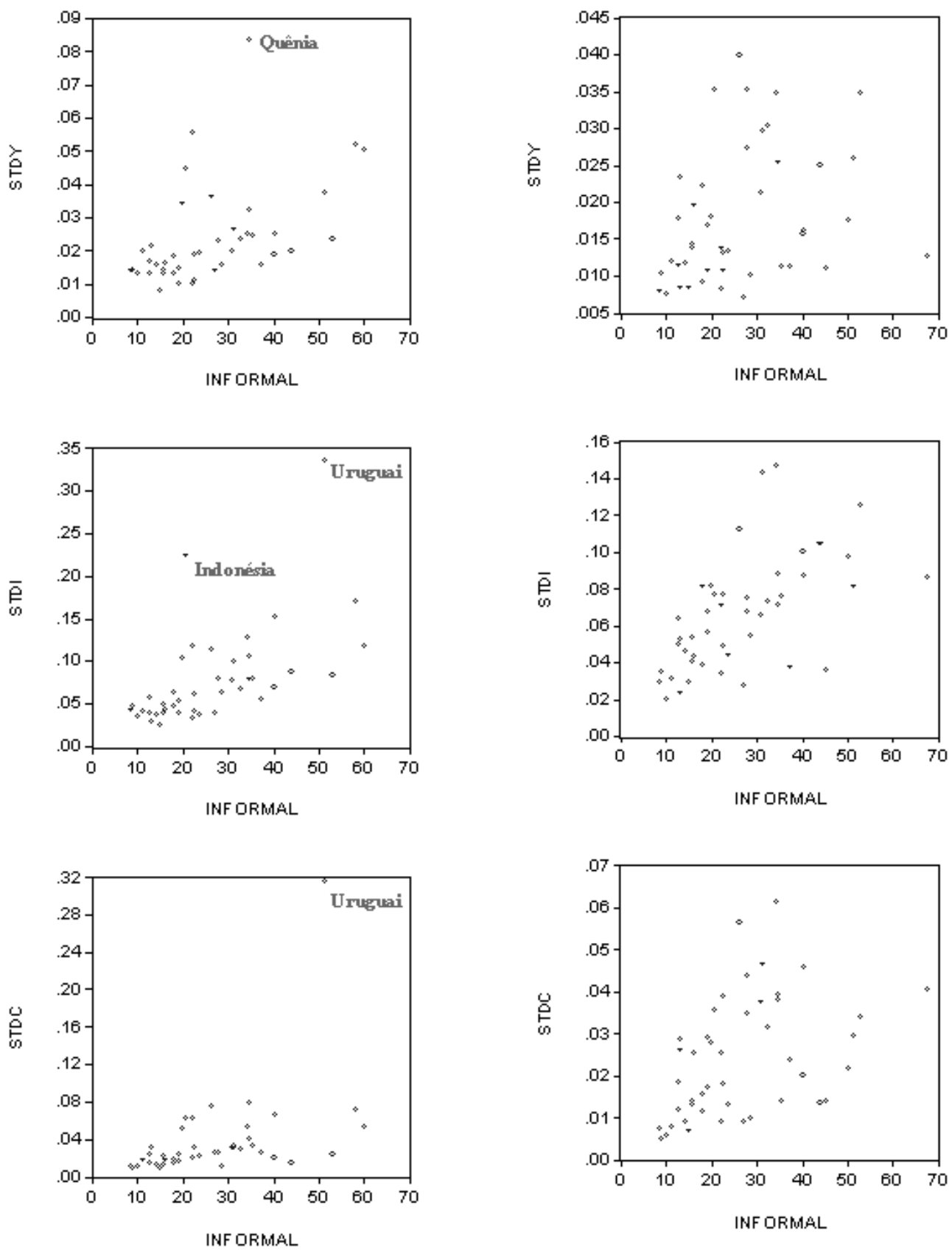

$1961-20102$

$1985-2[1] 2$ 


\section{CONCLUSÕES}

A expansão da economia informal tem sido freqüentemente apontada como fator que prejudica o crescimento econômico de um país. Este trabalho demonstrou que existe mais um motivo para tentar solucionar a questão da informalidade: países em que o setor informal é expressivo tendem a experimentar maior volatilidade na produção, no investimento e consumo privado durante os ciclos econômicos.

Como negócios no setor informal são em pequena escala, estes empreendimentos são normalmente improdutivos e têm acesso restrito ao crédito. As dificuldades na alavancagem financeira as tornam mais vulneráveis a flutuações na atividade econômica, já que não existe a possibilidade de neutralizar as contrações que ocorrem no fluxo de caixa durante períodos de recessão. Como as atividades do setor informal estão inter-relacionadas com as atividades do setor formal, quanto maior a dimensão da economia informal de um país, mais voláteis serão as flutuações na atividade econômica. Os resultados das análises de regressão apresentados neste trabalho corroboram essa conclusão: o tamanho do setor informal possui uma correlação positiva com a volatilidade dos ciclos econômicos, um resultado que é estatisticamente significante e economicamente relevante na maioria dos testes estatísticos conduzidos.

Os resultados apresentados sugerem que o componente exógeno do tamanho da economia informal, que é determinado por variáveis institucionais, como a tradição e respeito ao sistema legal e o controle da corrupção, contribui para aumentar a volatilidade dos ciclos econômicos. Ou seja, o presente artigo indica um outro canal através do qual as instituições afetam a volatilidade das atividades econômicas: instituições têm um papel fundamental na determinação da magnitude da economia informal e o crescimento da informalidade traz maior volatilidade para os ciclos econômicos.

A inclusão do tamanho da economia informal como determinante das flutuações econômicas reduz a importância de outras variáveis consideradas relevantes para a volatilidade dos ciclos econômicos. Como exposto acima, este fato reflete a relevância das características institucionais de um país para a volatilidade econômica. De uma forma geral, os resultados apresentados neste trabalho mantêm-se inalterados, independentemente da metodologia econométrica utilizada, das variáveis instrumentais empregadas e da exclusão de outliers.

Como flutuações significativas na atividade econômica são normalmente associadas a baixas taxas de crescimento econômico e baixos níveis de investimento direto (doméstico e estrangeiro), determinar as causas da volatilidade dos ciclos econômicos é de grande importância. Reformas institucionais que reduzam o custo para as empre- 
sas operarem no mercado formal são essenciais para reduzir o tamanho da economia informal e, conseqüentemente, diminuir a volatilidade dos ciclos econômicos.

\section{REFERENNCIAS BIBLIOGRÁFICAS}

Acemoglu, D.; Johnson, S.; Robinson, J.; Thaicharoen, Y. Institutional causes, macroeconomic symptoms: volatility, crises and growth. Journal of Monetary Economics, v. 50, p. 49-123, 2003.

Aisenman, J. Capital markets integration, volatility and persistence. Journal of Macroeconomics, v. 19, p. 217-236, 1997.

. Volatility, employment and the patterns of FDI in emerging markets. Journal of Development Economics, v. 72, p. 585-601, 2003.

Backus, D.K.; Kehoe, P.J.; Kydland, F.E. International real business cycles. Journal of Political Economy, v. 100, p. 745-775, 1992.

Bajada, C. Business cycle properties of the legitimate and underground economy in Australia. The Economic Record, v. 79, p. 397-411, 2003.

Banco Mundial. Governance indicators database. Washington, DC: The World Bank, 2002.

Doing Business Database. Washington, DC: The World Bank, 2003.

Barro, R. Economic growth in a cross section of countries. Quarterly Journal of Economics, v. 106, p. 407-444, 1991.

Basu, S.; Taylor, A. Business cycles in international historical perspective. NBER Working Paper, n. 7090, 1999.

Baxter, M.; King, R. Measuring business cycles: approximate band-pass filters for economic time series. Review of Economic and Statistics, v. 81, p. 575- 593, 1999.

Bernanke, B.; Gertler, M.; Gilchrist, S. The financial accelerator in a quantitative business cycle framework. NBER Working Paper, n. 6455, 1998.

Botero, J.; Djankov, S.; La Porta, R.; Lopez- De Silanez, F.; Shleifer, A. The regulation of labor. Quarterly Journal of Economics, v. 119, p. 1339-1382, 2004.

Dabla-Norris, E.; Feltstein, A. An analysis of the underground economy and its economic consequences. International Monetary Fund Working Paper, n. 23/03, 2003.

Denizer, C.; Iyigun, M.; Owen, A. Finance and macroeconomic volatility. Contributions to Macroeconomics, v. 2, n. 1, p. 1-30, 2002.

Farrell, D. The hidden dangers of the informal economy. The McKinsey Quarterly, n. 3, 2004. 
Ferreira da Silva, G. The impact of financial system development on business cycles volatility: cross-country evidence. Journal of Macroeconomics, v. 24, p. 233-253, 2002.

Fraser Institute. Economic Freedom of the World. Washington, DC: Fraser Institute, 1999.

Friedman, E.; Johnson, S.; Kaufmann, D.; Zoido-Lobaton, P. Dodging the grabbing hand: the determinants of unofficial activity in 69 countries. Journal of Public Economics, v. 76, p. 459-493, 2000.

Fundo Monetário Internacional. International financial statistics yearbook. Washington, DC: International Monetary Fund, várias edições.

Gertler, M.; Gilchrist, S. Monetary policy, business cycles, and the behavior of small manufacturing firms. Quarterly Journal of Economics, v. 59, p. 309-340, 1994.

Gërxhani, K. The informal sector in developed and less developed countries. Public Choice, v. 120, p. 267-300, 2004.

Giles, D.E.A. Measuring the hidden economy: implications for econometric modelling. The Economics Journal, v. 109, no. 456, p. 370-380, 1999.

Hall, R. Invariance properties of Solow's productivity residual. NBER Working Paper, n. 3034, 1989.

; Jones, C. Why do some countries produce so much more output per worker than others?. NBER Working Paper, n. 6564, 1998.

Heritage Foudation. Index of economic freedom. Washington, DC: Heritage Foundation, 1997.

Hubbard, R.G. Capital-market imperfections and investment. NBER Working Paper, n. $5966,1997$.

Johnson, S.; Kaufmann, D.; Zoido-Lobaton, P. Regulatory discretion and the unofficial economy. American Economic Review, v. 88, n. 2, p. 387-392, 1998.

. Corruption, public finances and the unofficial economy. World Bank Working Paper, n. 2169, 1999.

King, R.; Levine, R. Finance and growth: Schumpeter might be right. Quarterly Journal of Economics, v. 108, p. 717-737, 1993.

La Porta, R.; Lopez-De-Silanez, F; Shleifer, A.; Vishny, R. Law and finance. Journal of Political Economy, v. 108, p. 1113-1155, 1998.

Lippert, O.; Walker, M. The underground economy: global evidence of size and impact. Vancouver: The Fraser Institute, 1997.

Loayza, N. The economics of the informal sector: a simple model and some empirical evidence from Latin America. World Bank Policy Research Working Paper, n. $1727,1997$.

Maloney, W.F. Labor market structure in developing countries: time series evidence on competing views. The World Bank Working Paper, n. 1940, 1998. 
Informality revisited. The World Bank Working Paper, n. 2965, 2003.

Mckinsey \& Company. Eliminando as barreiras ao crescimento econômico e à economia formal no Brasil. São Paulo: McKinsey \& Company Inc., 2004.

Minsky, H. Stabilizing an unstable economy. New Haven: Yale University Press, 1986.

Ramey, G.; Ramey, V. Cross-country evidence on the link between volatility and growth. NBER Working Paper, n. 4959, 1994.

Ribeiro, R.N.; Bugarin, M.N.S. Fatores determinantes e evolução da economia submersa no Brasil. Estudos Econômicos, v. 33, n. 3, p. 435-466, 2003.

Schneider, F. The size of the shadow economies of 145 countries all over the world: first results over the period 1999 to 2003. IZA DP Discussion Paper, n. 1431, 2004.

Schneider, F; Enste, D.K. Shadow economies: size, causes and consequences. Journal of Economic Literature, v. 38, p. 77-114, 2000.

Schneider, F.; Klingmair, R. Shadow economies around the world: what do we know? CREMA Working Paper, n. 2004 - 03, 2004.

Stock, J.H.; Watson, M.W. Business cycle fluctuations in U.S. macroeconomic time series. NBER Working Paper, n. 6528, 1998.

Thomas, J. Quantifying the black economy: 'measurement without theory' yet again? The Economics Journal, v. 109, n. 456, p. 381-389, 1999. 
APÊNDICE 1 - DADOS ESTATÍSTICOS

\begin{tabular}{|c|c|c|c|c|c|c|c|c|}
\hline \multirow[b]{2}{*}{ País } & \multicolumn{4}{|c|}{1961 - 2002} & \multicolumn{4}{|c|}{1985 - 2002} \\
\hline & Informal & $\sigma_{\mathrm{Y}}$ & $\sigma_{\mathrm{I}}$ & $\sigma_{\mathrm{C}}$ & Informal & $\sigma_{\mathrm{Y}}$ & $\sigma_{\mathrm{I}}$ & $\sigma_{\mathrm{C}}$ \\
\hline Alemanha & 16,15 & 0,016 & 0,044 & 0,017 & 16,15 & 0,020 & 0,043 & 0,026 \\
\hline Argentina & 26,25 & 0,036 & 0,113 & 0,075 & 26,25 & 0,040 & 0,113 & 0,056 \\
\hline Austrália & 14,20 & 0,016 & 0,038 & 0,013 & 14,20 & 0,012 & 0,046 & 0,009 \\
\hline Áustria & 10,20 & 0,013 & 0,036 & 0,011 & 10,20 & 0,008 & 0,020 & 0,006 \\
\hline Bélgica & 22,10 & 0,010 & 0,033 & 0,020 & 22,10 & 0,008 & 0,034 & 0,009 \\
\hline Bolívia & & & & & 67,60 & 0,013 & 0,086 & 0,041 \\
\hline Brasil & 40,35 & 0,025 & 0,153 & 0,066 & 40,35 & 0,016 & 0,087 & 0,046 \\
\hline Canadá & 15,90 & 0,013 & 0,040 & 0,013 & 15,90 & 0,014 & 0,041 & 0,014 \\
\hline Chile & 20,05 & 0,034 & 0,104 & 0,051 & 20,05 & 0,018 & 0,082 & 0,028 \\
\hline Cingapura & & & & & 13,25 & 0,023 & 0,053 & 0,029 \\
\hline Colômbia & 40,20 & 0,019 & 0,069 & 0,020 & 40,20 & 0,016 & 0,100 & 0,020 \\
\hline Coréia do Sul & 27,80 & 0,023 & 0,080 & 0,026 & 27,80 & 0,027 & 0,068 & 0,035 \\
\hline Dinamarca & 17,95 & 0,013 & 0,048 & 0,018 & 17,95 & 0,009 & 0,039 & 0,016 \\
\hline Egito & 35,55 & 0,025 & 0,081 & 0,033 & 35,55 & 0,011 & 0,076 & 0,014 \\
\hline Equador & 34,75 & 0,032 & 0,079 & 0,040 & 34,75 & 0,025 & 0,088 & 0,038 \\
\hline Espanha & 22,60 & 0,011 & 0,042 & 0,031 & 22,60 & 0,011 & 0,049 & 0,018 \\
\hline Estados Unidos & 8,70 & 0,014 & 0,043 & 0,011 & 8,70 & 0,008 & 0,030 & 0,008 \\
\hline Filipinas & 43,95 & 0,020 & 0,089 & 0,015 & 43,95 & 0,025 & 0,105 & 0,014 \\
\hline Finlândia & 18,05 & 0,019 & 0,063 & 0,014 & 18,05 & 0,022 & 0,081 & 0,012 \\
\hline França & 15,10 & 0,008 & 0,026 & 0,008 & 15,10 & 0,008 & 0,030 & 0,007 \\
\hline Grécia & 28,60 & 0,016 & 0,063 & 0,012 & 28,60 & 0,010 & 0,055 & 0,010 \\
\hline Holanda & 13,05 & 0,022 & 0,030 & 0,031 & 13,05 & 0,008 & 0,023 & 0,026 \\
\hline Honduras & & & & & 50,20 & 0,018 & 0,097 & 0,022 \\
\hline Índia & 23,65 & 0,019 & 0,038 & 0,023 & 23,65 & 0,013 & 0,044 & 0,013 \\
\hline Indonésia & 20,60 & 0,045 & 0,224 & 0,063 & 20,60 & 0,035 & 0,077 & 0,036 \\
\hline Inglaterra & 12,60 & 0,013 & 0,041 & 0,014 & 12,60 & 0,011 & 0,050 & 0,012 \\
\hline Irlanda & 15,80 & 0,014 & 0,051 & 0,022 & 15,80 & 0,014 & 0,054 & 0,013 \\
\hline Israel & 22,35 & 0,056 & 0,117 & 0,062 & 22,35 & 0,014 & 0,071 & 0,026 \\
\hline Itália & 27,05 & 0,014 & 0,041 & 0,027 & 27,05 & 0,007 & 0,027 & 0,009 \\
\hline Japão & 11,15 & 0,020 & 0,041 & 0,018 & 11,15 & 0,012 & 0,032 & 0,008 \\
\hline Malásia & 31,35 & 0,027 & 0,101 & 0,032 & 31,35 & 0,030 & 0,144 & 0,047 \\
\hline México & 30,95 & 0,020 & 0,078 & 0,031 & 30,95 & 0,021 & 0,066 & 0,038 \\
\hline Nigéria & 58,25 & 0,052 & 0,170 & 0,072 & & & & \\
\hline Noruega & 19,05 & 0,010 & 0,055 & 0,024 & 19,05 & 0,011 & 0,068 & 0,029 \\
\hline
\end{tabular}




\begin{tabular}{|c|c|c|c|c|c|c|c|c|}
\hline \multirow[b]{2}{*}{ País } & \multicolumn{4}{|c|}{1961 - 2002} & \multicolumn{4}{|c|}{1985 - 2002} \\
\hline & Informal & $\sigma_{\mathrm{Y}}$ & $\sigma_{\mathrm{I}}$ & $\sigma_{\mathrm{C}}$ & Informal & $\sigma_{\mathrm{Y}}$ & $\sigma_{\mathrm{I}}$ & $\sigma_{\mathrm{C}}$ \\
\hline Nova Zelândia & 12,70 & 0,017 & 0,059 & 0,025 & 12,70 & 0,018 & 0,064 & 0,019 \\
\hline Paquistão & 37,35 & 0,016 & 0,056 & 0,026 & 37,35 & 0,011 & 0,038 & 0,024 \\
\hline Peru & 60,10 & 0,050 & 0,118 & 0,054 & & & & \\
\hline Polônia & & & & & 27,90 & 0,035 & 0,075 & 0,044 \\
\hline Portugal & 22,60 & 0,019 & 0,062 & 0,031 & 22,60 & 0,013 & 0,077 & 0,039 \\
\hline Quênia & 34,70 & 0,084 & 0,107 & 0,079 & 34,70 & 0,025 & 0,072 & 0,039 \\
\hline Sri Lanka & & & & & 45,25 & 0,011 & 0,036 & 0,014 \\
\hline Suécia & 19,15 & 0,015 & 0,039 & 0,017 & 19,15 & 0,017 & 0,057 & 0,017 \\
\hline Suiça & 9,00 & 0,014 & 0,049 & 0,009 & 9,00 & 0,010 & 0,035 & 0,005 \\
\hline Tailândia & 53,00 & 0,024 & 0,083 & 0,025 & 53,00 & 0,035 & 0,126 & 0,034 \\
\hline Turquia & 32,65 & 0,024 & 0,068 & 0,029 & 32,65 & 0,030 & 0,073 & 0,032 \\
\hline Uruguai & 51,25 & 0,037 & 0,336 & 0,316 & 51,25 & 0,026 & 0,081 & 0,029 \\
\hline Venezuela & 34,35 & 0,025 & 0,128 & 0,054 & 34,35 & 0,035 & 0,147 & 0,061 \\
\hline Mediana & 22,60 & 0,019 & 0,063 & 0,026 & 22,60 & 0,014 & 0,066 & 0,022 \\
\hline Média & 26,46 & 0,024 & 0,079 & 0,038 & 26,60 & 0,018 & 0,066 & 0,024 \\
\hline Mínimo & 8,70 & 0,008 & 0,026 & 0,008 & 8,70 & 0,007 & 0,020 & 0,005 \\
\hline Máximo & 60,10 & 0,084 & 0,336 & 0,316 & 67,60 & 0,040 & 0,147 & 0,061 \\
\hline Desvio Padrão & 13,371 & 0,015 & 0,058 & 0,048 & 13,461 & 0,009 & 0,031 & 0,014 \\
\hline $\mathrm{N}^{0}$ Obs. & 42 & 42 & 42 & 42 & 45 & 45 & 45 & 45 \\
\hline
\end{tabular}

